\title{
Relation of speed of a mile run, maximum energy cost of running, and maximum oxygen consumption: a field study
}

\author{
Sunil Kumar Das and Abhijit Dutta \\ Exercise, Sports and Cardiorespiratory Physiology Laboratory, Department of Physiology, University Colleges of \\ Science and Technology, Calcutta, India
}

\begin{abstract}
Objective-To compare the maximum energy cost of running (MECR) estimated from the speed of a mile run and the maximum oxygen consumption $\left(\mathrm{VO}_{2 \max }\right)$ with a field step test.

Methods-MECR was defined as the maximum $\dot{\mathrm{V}} \mathrm{O}_{2}$, derived from the equation $\mathrm{VO}_{2}=5.3 \mathrm{mph}+3.9$ $\left(\mathrm{ml} \cdot \mathrm{min}^{-1} \cdot \mathbf{k g}^{-1}\right)$, when the subject performs a maximal, exhausting run and attains maximum speed. The equation is based on a straight line relation between speed and $\dot{\mathrm{V}} \mathrm{O}_{2}$. In this study MECR was obtained from a mile run and was compared with $\mathrm{VO}_{2 \max }$ by extrapolation using a step test. Both tests were performed in the field.

Results and conclusions-The variation in the MECR with $\dot{\mathrm{V}} \mathrm{O}_{2 \max }$ was within $\pm 10 \%$. It therefore appears that the speed of a mile run is a good criterion of $\dot{V} \mathrm{O}_{2 \max }$ or estimated MECR for the measurement of physical fitness, and for the selection, recruitment, and assignment of an individual in field sports.

(Br J Sports Med 1995; 29: 271-272)
\end{abstract}

Keywords: mile run; energy cost of running; running speed; maximum oxygen consumption; step test; field study

We estimate the maximum energy cost of running (MECR) from the straight line relation between speed (in mph) and its energy cost (as $\mathrm{VO}_{2}$ in $\mathrm{ml} \cdot \mathrm{min}^{-1} \cdot \mathrm{kg}^{-1}$ ), that is, the greater the speed, the greater is the $\mathrm{VO}_{2}$; thus maximum speed is equivalent to maximum energy cost. MECR may therefore be defined as the $\mathrm{VO}_{2}$ at which speed is the maximum that can be sustained for at least a mile run. Speed expressed in $\mathrm{mph}$ is linear with $\dot{\mathrm{VO}} \mathrm{O}_{2}$ (in $\mathrm{ml} \cdot \mathrm{min}^{-1} \cdot \mathrm{kg}^{-1}$ ) at $0 \%$ treadmill inclination, and the latter may be derived by the point slope method as $\mathrm{VO}_{2}=5.3 \mathrm{mph}-3.9{ }^{1}$ Thus MECR $=5.3 \mathrm{mph}+3.9$ when the speed is maximum. $\mathrm{VO}_{2 \max }$ is defined as maximum $\dot{\mathrm{VO}}\left(\mathrm{ml} \cdot \mathrm{min}^{-1} \cdot \mathrm{kg}^{-1}\right)$ obtained by work to exhaustion and is also known as the aerobic capacity of the maximum physical work capacity, which is measured by extrapolation in the field with the step test protocol.

The aim of the present study was to compare the MECR estimated from the speed of a mile run with $\dot{\mathrm{V}} \mathrm{O}_{\text {max }}$ extrapolated from step testing in the field.

Address for correspondence: Dr Sumil Kumar Das, Department of Physiology, University Colleges of Science and Technology, 92 Acharya Prafulla Chandra Road, Calcutta 700009, India

\section{Methods}

Eighty three subjects ranging in age from 13 to 17 years volunteered for the present study. Most of the subjects were physically active and usually participated in school games and sports. They were selected from a school situated in a suburban area of Calcutta. A 400 metre grass track was marked out in a football ground and the subjects were given an initial trial of both a step test and a mile run to familiarize them with the nature of the experiment several days before the actual day of estimation.

$\dot{\mathrm{V}} \mathrm{O}_{2 \max }$ was determined by extrapolation using the step test as described earlier. ${ }^{2}$ The step test was done on a $40 \mathrm{~cm}$ step, with step rate varying from 15 to 30 up/down steps per minute in accordance with a metronome. Step frequencies were $15,17.5,20,22.5,25$, 27.5 , or 30 per min and the $\mathrm{VO}_{2}$ values $\left(\mathrm{ml} \cdot \mathrm{min}^{-1} \cdot \mathrm{kg}^{-1}\right)$ obtained at these rates were $22.5,24.5,27.5,32.5,35.5$, and $38.5 \mathrm{ml} \cdot \mathrm{min}^{-1} \cdot \mathrm{kg}^{-1}$ ), respectively, from the nomogram of Margaria et al. ${ }^{3}$ Exercise heart rate was recorded using an electronic stop watch as the time taken for 5 beats, which was then converted to beats $\cdot \mathrm{min}^{-1}$. This heart rate was taken immediately after the end of each 5 min step, when it is almost equal to the exercise heart rate. ${ }^{2}$ At the end of four or five step test sessions, when heart rate reached $150-160$ beats $\cdot \mathrm{min}^{-1}$, all the subjects rested for half an hour. After resting the subjects ran on the track and the timing of a mile run was recorded with an electronic stop watch. The subjects were motivated to exert maximum effort in the run and showed excellent cooperation. From the timing of the mile run, their speed was calculated in mph. MECR was calculated from the speed.

$\dot{\mathrm{VO}}_{2 \max }$ was predicted by plotting the several pairs of heart rate and $\dot{\mathrm{V}} \mathrm{O}_{2}$ values as a straight line and extrapolating to maximum heart rate (MHR), which on average was 205 beats $\cdot \mathrm{min}^{-1}$ at a mean age of 15 years ( $\mathrm{MHR}=220-$ age in years). The $\mathrm{VO}_{2}$ corresponding to 205 beats $\cdot \mathrm{min}^{-1}$ is said to be the $\dot{\mathrm{VO}}{ }_{\text {max }}$ (extrapolated). No individual age-predicted maximum heart rate was considered. This study was done in the winter season between 7 am and 9 am when the temperature varied between 20 and $25{ }^{\circ} \mathrm{C}$, relative humidity was $30-65 \%$, and barometric pressure was $760-766 \mathrm{~mm} \mathrm{Hg}$. 
Table 1. Physical characteristics, speed, maximum energy cost of running (MECR), and $\mathrm{VO}_{2 \max }$. Values are means (SD)

\begin{tabular}{ccccccc}
\hline & $\begin{array}{c}\text { Age } \\
\text { (years) }\end{array}$ & $\begin{array}{c}\text { Height } \\
(\mathrm{cm})\end{array}$ & $\begin{array}{c}\text { Weight } \\
(\mathrm{kg})\end{array}$ & $\begin{array}{c}\text { Speed } \\
(\mathrm{mph})\end{array}$ & $\begin{array}{c}\mathrm{MECR}^{*} \\
\left(\mathrm{ml} \cdot \mathrm{min}^{-1} \cdot \mathrm{kg}^{-1}\right)\end{array}$ & $\begin{array}{c}\mathrm{VO}_{2 \max } \\
\left(\mathrm{ml}^{2} \cdot \mathrm{min}^{-1} \cdot \mathrm{kg}^{-1}\right)\end{array}$ \\
\hline 83 & $15(1.7)$ & $163(6.1)$ & $48.2(7.3)$ & $8.4(1)$ & $48.4(5.6)$ & $48.0(6.2)$ \\
\hline
\end{tabular}

${ }^{*} \mathrm{MECR}=5.3 \mathrm{mph}+3.9\left(\mathrm{ml} \cdot \mathrm{min}^{-1} \cdot \mathrm{kg}^{-1}\right)$.

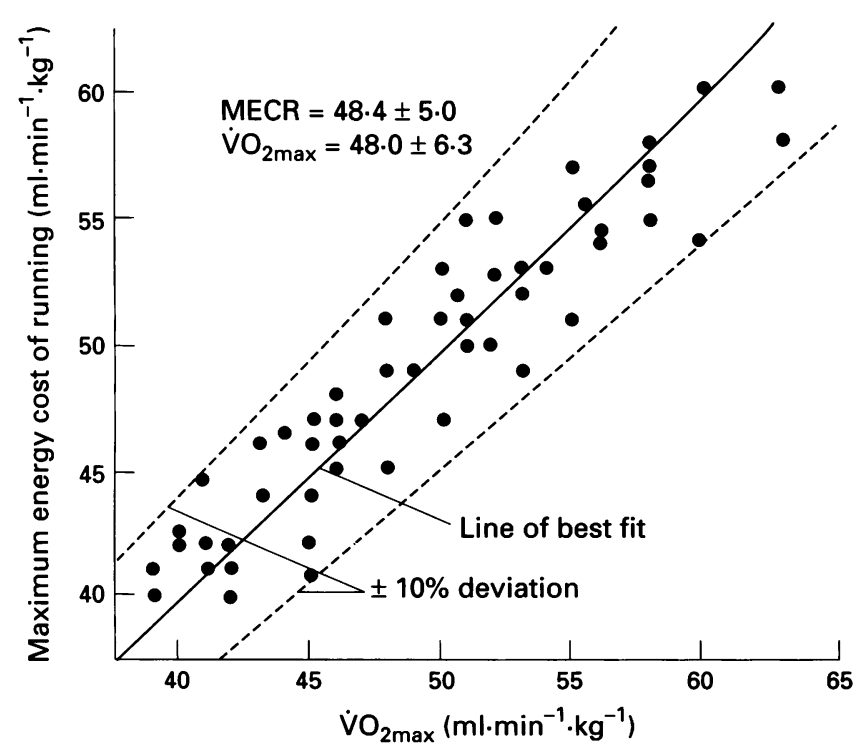

Figure 1.

Statistical analysis of the data was performed by a statistical calculator for determination of product moment correlation $(r)$ and mean (SD).

\section{Results}

The results are shown in Table 1 and Figure 1. Table 1 shows mean and SD of the physical characteristics, $\mathrm{MECR}$, and $\mathrm{VO}_{2 \max }$. Figure 1 shows the relation between MECR and $\mathrm{VO}_{2 \max }$ with the line of best fit and the $10 \%$ deviation. The product moment correlation was highly significant $(r=0.923, P<0.001)$. There was no significant difference between MECR and $\dot{V O O}_{2 \max }$ when compared using a $t$ test.

\section{Discussion}

The distance run in 12 minutes or time of 1.5 mile run have been shown to be highly correlated with $\mathrm{VO}_{2 \max }{ }^{45}$ and various studies had been carried out to establish the relation between distance run and $\mathrm{VO}_{2 \max }{ }^{4-10}$ In the present study $\dot{\mathrm{VO}}_{2 \max }$ and MECR were almost identical and the correlation did not vary by more than $\pm 10 \%$. We have therefore established that MECR calculated from the speed of a mile run is almost same as $\mathrm{VO}_{2 \max }$. Thus this study simplifies the field test determination of $\dot{\mathrm{V}} \mathrm{O}_{2 \max }$ from the speed of a mile run. This will be of value for coaches, who need to know the maximum speed of athletes under training or of competitors in various sports and games in which endurance is a good criterion for selection, training, and improvement. The greater the cardiorespiratory fitness, The greater is the speed of a mile run. The speed of a mile run is a good measure of physical fitness and it may be expressed as $\mathrm{MECR}$. Extrapolated $\dot{\mathrm{V}} \mathrm{O}_{2 \max }$ was almost same when determined from treadmill exercise, and this has been verified recently in eight young male and female subjects (Das SK, Bhattacharya G, Mahapatra S, unpublished data).

\section{References}

1 Lamb RD. Physiology of exercise, 2nd ed. New York: Macmillan, 1984: 179.

2 Das SK, Bhattacharya G, Mahapatra S. Application of Margaria equation in determination of $\mathrm{VO}_{2 \max }$ of Indian women. Ind J Physiol Allied Sci 1994; 48: 45-7.

3 Margaria R, Aghemo P, Rovelli E. Indirect determination of maximal oxygen consumption in man. J Appl Physiol 1965; 20: 1070-3.

4 Cooper $\mathrm{KH}$. A means of assessing maximal oxygen intake. Correlation between field and treadmill testing. JAMA 1968; 203: 201-4.

5 Cooper $\mathrm{KH}$. The aerobic program for total well-being. Toronto: Banton Books, 1982.

6 Maksud ME, Contts KD. Application of the Cooper twelveminute run-walk to young males. Res $Q 1971 ; 42: 54-8$.

7 Burger SC, Bertram SR, Stewart RI. Assessment of the $2.4 \mathrm{kM}$ run as a predictor of aerobic capacity. S Afr Med J 1990; 78: 327-9.

8 MacNaughton L, Croft R, Pennicott J, Long T. The 5 and 15 minute runs as predictors of aerobic capacity in high school students. J Sport Med Phys Fitness 1990; 30: 24-8.

9 Zwiren LD, Freedson PS, Ward A, Whilke S, Rippe JM. Estimation of $\dot{\mathrm{V}} \mathrm{O}_{2 \mathrm{xa}}$ : a comparative analysis of five exercise tests. Res Exerc Sport 1990; 62: 73-8.

10 Anderson GS. A comparison of predictive tests of aerobic capacity. Can J Sport Sci 1992; 17: 304-8. 